\title{
DISTRIBUCIÓN FUNCIONAL DE LA RENTA Y COSTES LABORALES EN GIPUZKOA: UN ESTUDIO EMPÍRICO PARA LA REDUCCIÓN DEL TIEMPO DE TRABAJO ${ }^{1}$
}

\author{
Verónica Castrillón Serna \\ Jose Mari Zendoia SAInZ \\ Jon Bernat Zubiri Rey \\ Departamento de Economía Aplicada I \\ Euskal Herriko Unibertsitatea / Universidad del País Vasco (UPV/EHU)
}

DOI: $10.1387 /$ lan-harremanak.16564

\section{ABSTRACT}

En este artículo se analiza la evolución seguida por la distribución funcional de la renta y los costes laborales unitarios de cara a justificar la viabilidad y la financiación de una reducción del tiempo de trabajo en Gipuzkoa. En el estudio de la distribución, se evalúa el efecto que la fiscalidad directa ha ejercido sobre las rentas procedentes de trabajo y las rentas de capital, de acuerdo a sus participaciones en el PIB $y$ atendiendo al principio de equidad redistributiva. Los costes laborales unitarios se han calculado en términos reales, nominales y deflactados y se presentan los resultados desagregados en 38 sectores industriales. En el análisis se ha incluido el último

${ }^{1}$ La autoría de este artículo está indicada por orden alfabético, justificada en el trabajo equitativamente compartido de análisis del reparto del tiempo de trabajo, en el marco del Proyecto de Investigación "Reparto del empleo y del tiempo de trabajo: efectos en la fiscalidad y tratamiento jurídico», financiado por el Departamento de Innovación de la Diputación Foral de Gipuzkoa, a ejecutar entre el 22-12-2014 y el 30-10-2015. 
ciclo expansivo de la economía (1995-2007) y los cinco primeros años de la recesión iniciada en 2008.

Palabras clave: distribución de la renta, fiscalidad directa, costes laborales, reducción del tiempo de trabajo, Gipuzkoa.

This article discusses the evolution followed by the functional distribution of income and unit labour costs in Gipuzkoa, in order to guide the feasibility and financing of a reduction in working time. In the study of the distribution, the effect has exercised direct taxation on income from labor and capital income, according to their shares in GDP and based on the principle of redistributive equity is evaluated. Unit labor costs are calculated in real terms, nominal and deflated and the results are presented by 38 industrial sectors. The analysis has included the last expansionary cycle of the economy (1995-2007) and the first five years of the recession that began in 2008.

Keywords: Income distribution; Direct taxation; Labour costs; Reduction of working time, Gipuzkoa.

Artikulu honetan, errentaren banaketa funtzionalaren eta lan-kostu unitarioen garapena aztertu da, Gipuzkoan lanaldi murrizketaren bideragarritasuna eta finantziazioa justifikatzeko. Banaketaren azterketan, zerga-sistema zuzenak lanetik eratorritako errentetan eta kapital-errentetan izan duen eragina baloratzen da, BPGd-ean duten partaidetzaren arabera eta berbanatze berdintasun printzipioa kontuan harturik. Lan-kostu unitarioak balio errealetan, nominaletan eta deflaziobalioetan kalkulatu dira eta emaitzak 38 industria-sektoretan banandurik aurkezten dira. Analisian ekonomiaren azken ziklo hedakorra (1995-2017) eta 2008an hasitako gainbeheraren lehen bost urteak barneratu ditugu.

Hitz gakoak: errentaren banaketa, zerga-sistema zuzena, lan-kostuak, lanaldi murrizketa, Gipuzkoa. 


\section{Introducción}

Este artículo es fruto de un informe encargado por el Departamento de Innovación de la Diputación Foral de Gipuzkoa para el estudio de políticas de Reducción del Tiempo de Trabajo (RTT), con el objetivo de enfrentar la situación de desempleo sostenido y subempleo que la sociedad gipuzkoana viene padeciendo de manera persistente tras el inicio de la crisis. En las series se ha incluído el último ciclo expansivo de la economía (1995-2007) y los cinco primeros años de la recesión (2008-12), datos disponibles en Eustat hasta su actualización en Octubre de 2015, fecha en que se entregó el informe.

El presente trabajo continúa el diagnóstico ya desarrollado en Castrillón et al. (2016a) y consta de dos secciones. En la primera se analiza la distribución funcional de la renta antes y después de impuestos directos. El estudio de la distribución y el impacto de la fiscalidad directa nos permitirá orientar las propuestas de financiación de las políticas de RTT que se plantean en Castrillón et al. (2016d). En la segunda parte se analizan los costes laborales unitarios (CLU). Para el cálculo de los CLU y el estudio de su comportamiento, tanto desde el punto de vista de la competitividad como de la distribución del ingreso, se han utilizado tres metodologías, obteniéndose los CLU nominales, reales y deflactados. Su evolución se ha analizado en valores agregados y por sectores industriales, lo que nos ha permitido identificar, en Castrillón et al. (2016c), los sectores en los que las políticas de RTT pueden tener mayor potencialidad en la creación de puestos de trabajo.

\section{Distribución funcional de la renta}

Aunque existen diferentes enfoques desde los que examinar los mecanismos que operan en la distribución entre las rentas del trabajo y las del capital (distribución funcional), no es el objetivo de este trabajo abordar un debate teórico; sí en cambio nos interesa analizar, tanto la distribución funcional, como el impacto distributivo que la fiscalidad directa ejerce sobre la misma:

Dejando pendiente de dilucidación dichos mecanismos, no parece haber posibilidad de dudas acerca de que es en ese proceso productivo cuando se determina 
el monto a repartir y, por supuesto, cómo hacerlo. Luego de ello podrán existir mecanismos variados con los cuales la sociedad puede «interferir» en tal reparto. Sin duda, uno de los más importantes es el ejercido por la acción estatal que puede imponer cargas fiscales para proporcionar bienes o servicios (...) de modo tal que puedan moderarse las desigualdades surgidas del proceso económico vigente. (Lindenboim, 2008: 86)

El cálculo de la presión fiscal efectiva ejercida sobre ambas rentas lo haremos de acuerdo a sus su participación en el PIB y teniendo presente que:

La distribución de la renta constituye un elemento fundamental para conocer las dinámicas que alimentan el crecimiento económico y el bienestar de la población. No en vano, el principio redistributivo se encuentra en la Constitución española que establece la obligación de todos de contribuir al sostenimiento de los gastos públicos de acuerdo con su capacidad económica, así como la asignación equitativa de los recursos públicos (art. 31), del mismo modo que exige a los poderes públicos la promoción de las condiciones favorables para el progreso social y económico (art. 40). (CES, 2013: 11)

Respecto al efecto de la distribución personal de la renta en el crecimiento económico, tanto la $\mathrm{OCDE}(2015)^{2}$ como el propio $\mathrm{FMI}^{3}$ se han sumado a las tradiciones que alertan de que la creciente desigualdad tiene una incidencia negativa en el crecimiento, efecto que también tiene lugar en el caso de la distribución funcional, tal y como afirman Álvarez y Luengo (2011: 18):

Poner el análisis en la distribución (funcional) de la renta en la UE en relación con la competitividad de estas economías no sólo cuestiona el axioma de que un mayor crecimiento salarial se traduce en pérdidas de competitividad y, con ello, en ausencia de modernización productiva. Permite además evidenciar que un cambio en los patrones de distribución de la renta que impulse las rentas salariales y, con ello, la demanda agregada, (...) parece perfectamente viable, en la medida en que la financiación de la actividad productiva se ha desvinculado parcialmente del fuerte crecimiento experimentado por las rentas del capital (en la UE) durante el periodo 1996-2009.

\subsection{Evolución de las rentas en el PIB a precios de mercado}

La primera dificultad para analizar la evolución de las rentas en Gipuzkoa la hemos encontramos en la no disponibilidad de datos: en el EUSTAT se ofrecen

2 Véase OECD (2015) In It Together: Why Less Inequality Benefits.

3 La directora gerente del Fondo Monetario Internacional (FMI), Christine Lagarde, en un debate sobre la concentración de la riqueza en el Foro Económico Mundial (Davos, 2015) declaró que los economistas del FMI han hecho investigaciones que han concluido en que la «distribución de la riqueza es importante en sí, porque aumentar los ingresos de los pobres tiene un efecto multiplicador que no se produce si se aumenta el ingreso de los que ya son ricos» (ED, Economía digital, 2015). 
series para Gipuzkoa correspondientes al PIBpm y a la Remuneración de asalariados, pero no existen datos disponibles ni para el Excedente bruto de explotación, ni para el Excedente neto, ni tampoco para los Impuestos netos sobre producción e importaciones.

Teniendo en cuenta los componentes básicos del PIBpm en rentas:

$$
\begin{gathered}
\text { PIBpm = remuneración de asalariados }+ \\
+ \text { excedente bruto de explotación (incluye renta mixta }{ }^{4} \text { ) }+ \\
+ \text { impuestos netos sobre producción e importaciones }
\end{gathered}
$$

Como sí están calculadas las siguientes partidas:

—impuestos netos sobre producción e importaciones C.A. de Euskadi,

— impuestos netos sobre los productos C.A. de Euskadi,

— impuestos netos sobre los productos Gipuzkoa.

para estimar los impuestos netos sobre producción e importaciones de Gipuzkoa, hemos obtenido los porcentajes que representan los Impuestos netos sobre producción e importaciones frente a los Impuestos netos sobre los productos en el periodo analizado en la C.A. Euskadi y hemos aplicado los coeficientes de cada año a los Impuestos netos sobre los productos de Gipuzkoa.

Una vez estimados los Impuestos netos sobre producción e importaciones, el Excedente bruto de explotación se obtiene por la diferencia:

excedente bruto de explotación $=$ PIBpm - remuneración de asalariados - Impuestos netos sobre producción e importaciones

La participación de cada componente en el PIB se recoge en la Figura 1.

En todo el periodo se observa una distribución favorable a los salarios, que se acentúa a partir de la crisis de 2008, siendo: entre 1995 y 2001 de un $46 \%$ frente a un 44\%; en 2010, año de máxima diferencia entre la participación de ambas rentas, de un $49 \%$ frente a un $41 \%$; y de un $49 \%$ frente a un $43 \%$ en 2012, al final del periodo.

\footnotetext{
${ }^{4}$ Dados los datos disponibles, carecemos de información suficiente como para calcular (o estimar) el valor de la renta mixta y desagregarla del excedente bruto.
} 
Figura 1

PIBpm rentas Gipuzkoa (I)

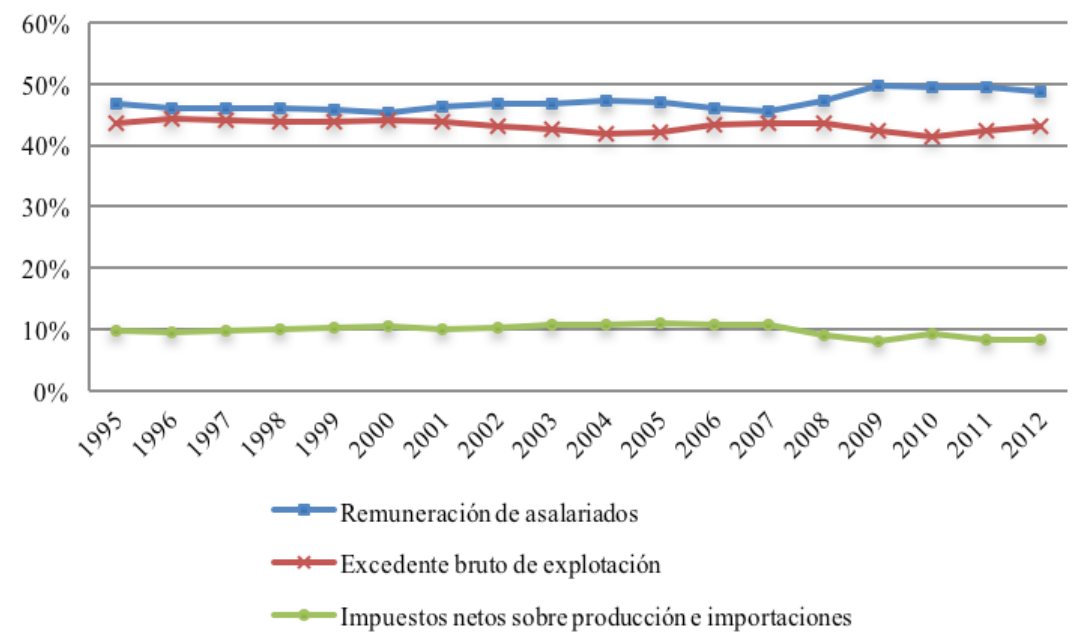

Fuente: elaboración propia a partir de datos de EUSTAT.

Figura 2

PIBpm rentas CA Euskadi

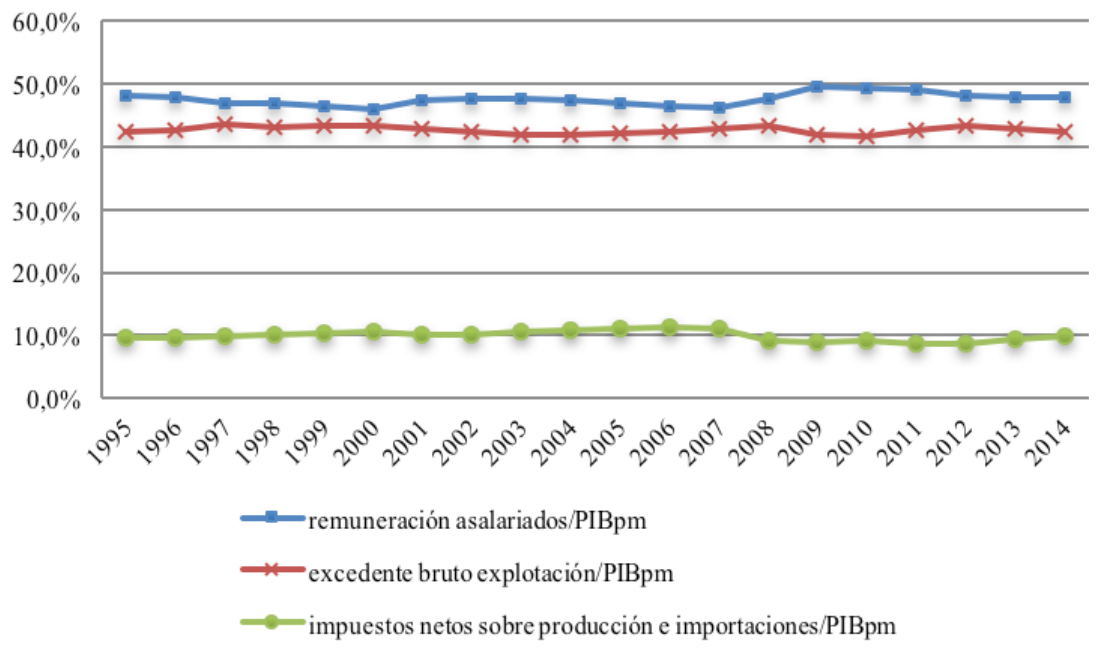

Fuente: EUSTAT. 
El comportamiento de la participación en el PIB de estas rentas es bastante similar para la CA de Euskadi en el mismo periodo, tal y como se muestra en la Figura 2, que hemos obtenido a partir de las series ofrecidas en el EUSTAT y calculando:

excedente bruto de explotación $=$ excedente neto de explotación + consumo de capital fijo

Otra descomposición en rentas más desagregada para el PIBpm de Gipuzkoa está representada en la Figura 3, donde:

PIBpm = excedente neto de explotación + consumo de capital fijo + salarios netos + + cotizaciones a la Seguridad Social + impuestos netos sobre producción e importaciones siendo:

salarios netos $=$ remuneración de asalariados - cotizaciones a la SS $(28,3 \%)$ excedente neto de explotación $=$ excedente bruto de explotación - consumo de capital fijo.

Tampoco hay datos en EUSTAT del consumo de consumo de capital fijo en Gipuzkoa; para estimarlo, hemos calculado el porcentaje excedente neto de explotación/excedente bruto de explotación en la C.A. de Euskadi para el mismo periodo y hemos aplicado los coeficientes de cada ańo al excedente bruto de explotación de Gipuzkoa.

Figura 3

PIBpm rentas Gipuzkoa (II)

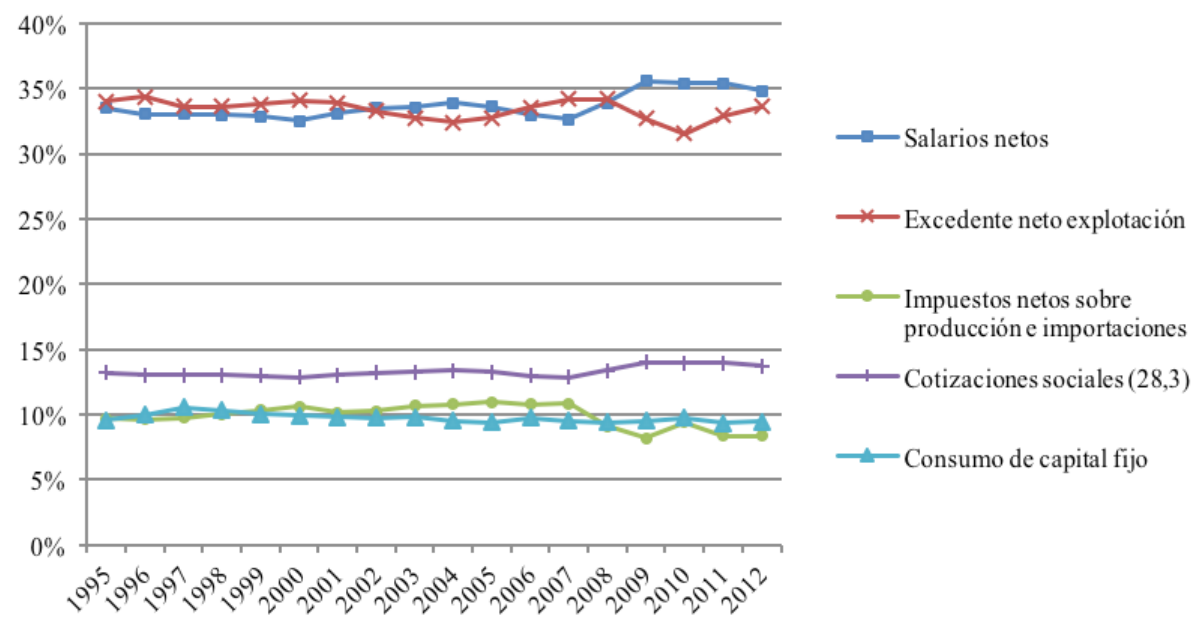

Fuente: elaboración propia a partir de datos de Eustat. 
En esta despomposición en rentas para el PIB, se ha descontado del excedente bruto de explotación el consumo de capital fijo para obtener el excedente neto de explotación y se ha procedido de la misma manera con las rentas salariales: para obtener los salarios netos, se ha descontando las cotizaciones a la SS de la remuneración a los asalariados en concepto de "consumo de fuerza trabajo» ${ }^{5}$.

A lo largo de la serie, los salarios netos se mantienen en un 33\% durante casi todo el periodo, alcanzando un máximo de 36\% en 2009 y valores de 35\% entre 2010 y 2012. El excedente neto de explotación se manteniene en un valor máximo y modal de 34\%, alcanzando un mínimo del 32\% en 2004 y 2010. Como en la anterior descomposición, PIBpm rentas Gipuzkoa (I), la diferencia a favor de salarios también es algo más pronunciada a partir de 2008 y máxima en 2010 (35\% frente a 32\%). La distribución entre el excedente de explotación y los salarios es más equitativa en términos netos que en términos brutos. Por una parte, hasta 2009 la distribución neta resulta favorable al excedente y no a salarios, con un $34 \%$ frente al $33 \%$; por otra, la máxima diferencia, que ahora se observa en 2010 y también resulta a favor de salarios, en lugar de ser de 50\% frente a $42 \%$, resulta de un $35 \%$ frente a un $32 \%$.

\subsection{Impuestos directos}

Tras analizar la información sobre macromagnitudes contables en torno al PIBpm disponible en EUSTAT, pasamos a estudiar los impuestos directos sobre estas rentas a partir de los datos ofrecidos por la Hacienda Foral de Gipuzkoa referentes a IRPF e Impuesto de sociedades.

En primer lugar consideramos los rendimientos netos sobre el trabajo, cuyos impuestos directos devengados hemos estimado por el $85 \%$ de la cuota líquida

\footnotetext{
5 Este tratamiento contable de las cotizaciones (el hecho de no considerarlas parte de los ingresos salariales aunque supongan un coste salarial para las empresas) puede justificarse a nuestro juicio, tanto por las disfunciones redistributivas que ocasionan (Fernández Díaz, Andrés, 2008:30): «El principio de solidaridad implica precisamente que el derecho a las prestaciones es proporcional a las necesidades $y$, en consecuencia, no puede ser proporcional a las cotizaciones, porque el principio de solidaridad postula que contribuyan más a la Seguridad Social los que tiene menos necesidad de ayuda. Pues bien es en ese aspecto de la solidaridad donde se pone de manifiesto también la disfunción originada por el sistema de financiación basado en las cotizaciones ya que se puede constatar cómo en la realidad sólo algunas categorías de personas, grupos, empresas y sectores económicos soportan el «deber de solidaridad", en tanto que otros, con situaciones económicas mejores que las de los anteriores, se libran de ese deber", como atendiendo a la clasificación de su naturaleza jurídica: (pags. 31-32) «la cuota vista, desde el punto de vista económico, se considera como parte del factor trabajo, es decir, es uno más de los costes de producción, relacionados con el coste de la mano de obra y repercutiendo en el precio final del producto (...) las teorías jurídico-públicas han llevado a interpretar la cuota como tributo (...) La naturaleza especial de la cuota (...) obliga a considerar en último término a la cuota como una categoría jurídica sui géneris, con un régimen jurídico especial y peculiar». Además, en coherencia con el siguiente apartado en que se evalúa la presión fiscal, las cotizaciones a la SS no forman parte de la base de cotización del IRPF.
} 
de las declaraciones de IRPF para todo el periodo y cuyo resultado se muestra en la Figura 4.

Figura 4

Impuestos directos sobre rentas del trabajo

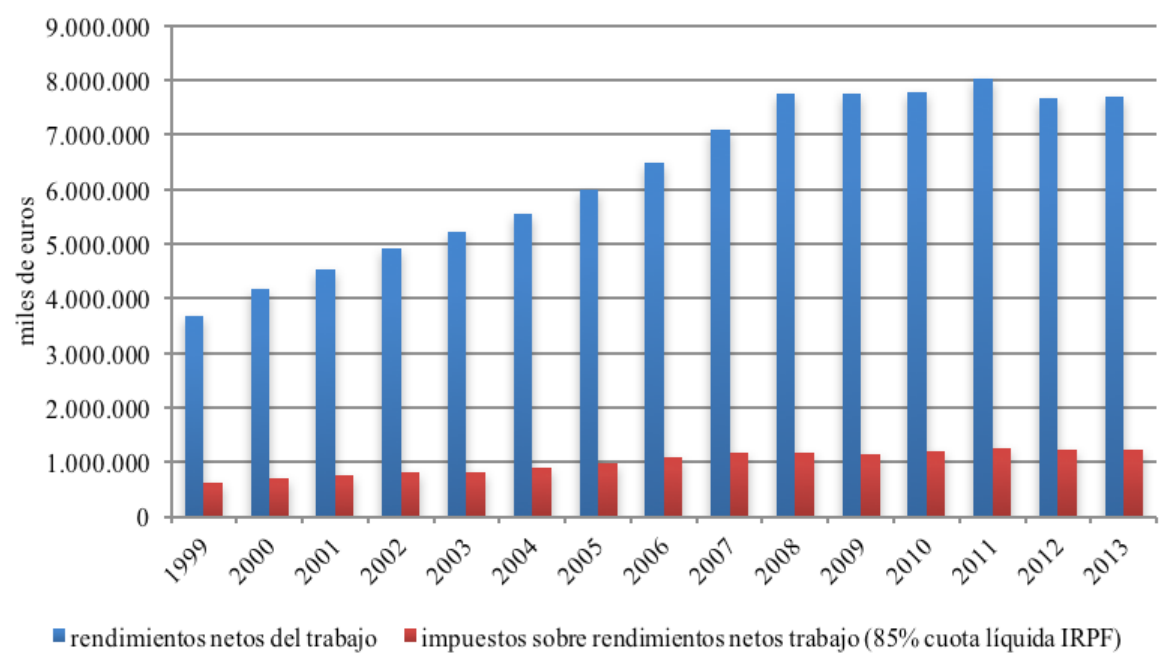

Fuente: elaboración propia a partir de datos de Hacienda Foral de Gipuzkoa.

En la Figura 5 están representados resultados semejantes para las rentas de capital. Dado que el excedente neto de explotación del PIBpm incluye tanto los beneficios de las empresas como la renta mixta (ver nota 3) optado por agregarlos también en este apartado en aras de una mejor comparabilidad de resultados.

El excedente neto fiscal lo hemos obtenido:

excedente neto fiscal $=$ beneficio antes de impuestos de empresas con base liquidable positiva (impuesto sociedades) + renta mixta (IRPF)

Siendo:

renta mixta $=$ rendimientos netos no salariales + base liquidable ahorro rendimientos netos no salariales $=$ total rendimientos netos - rendimientos netos del trabajo. 
Figura 5

\section{Componentes del Excedente neto fiscal}

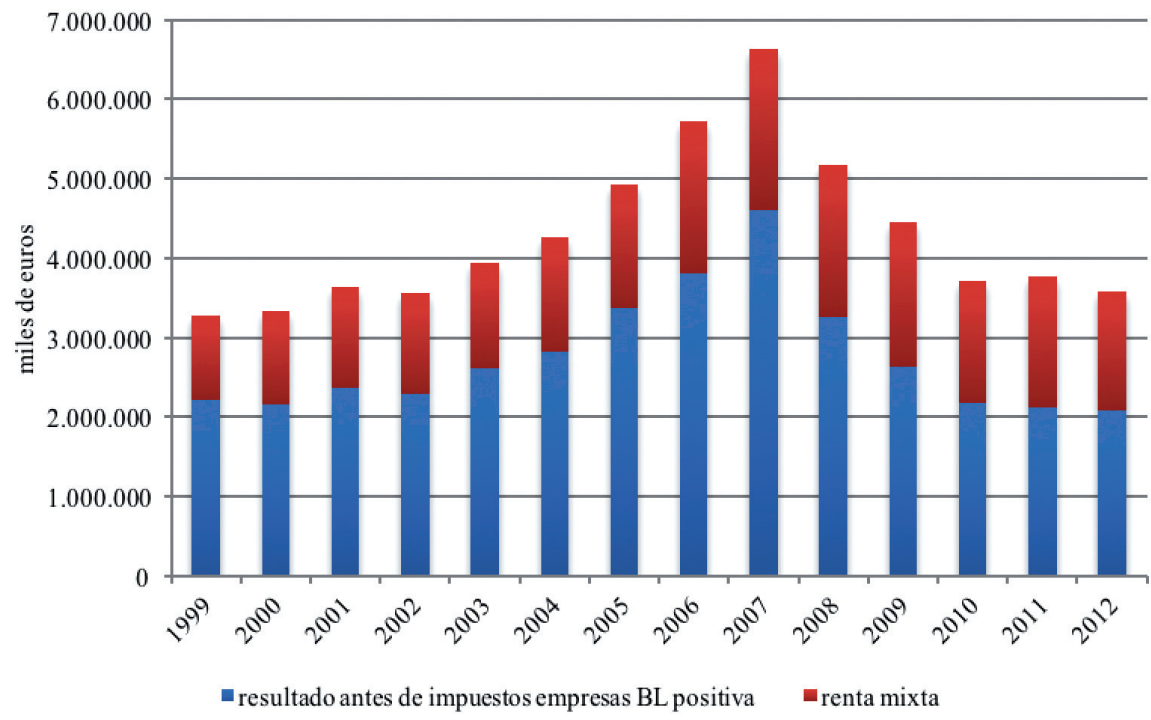

Fuente: elaboración propia a partir de datos de Hacienda Foral de Gipuzkoa.

Figura 6

Impuestos directos sobre el excedente neto fiscal

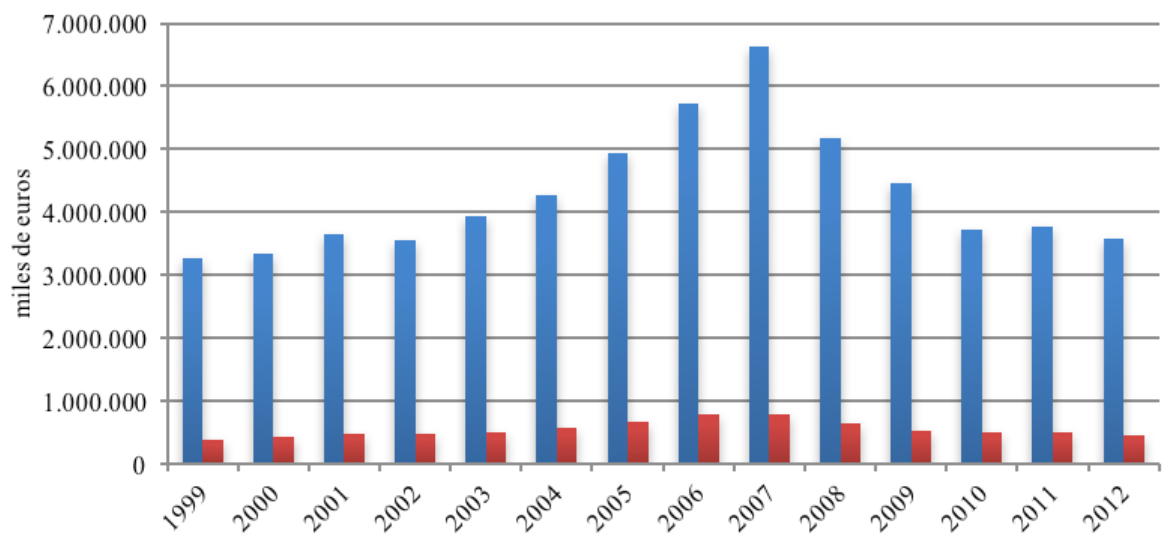

घexcedente neto fiscal

- impuestos sobre excedente neto físcal (impuesto sociedades $+15 \%$ cuota líquida IRPF)

Fuente: elaboración propia a partir de datos de Hacienda Foral de Gipuzkoa. 
En la Figura 6 tenemos los impuestos directos junto al excedente neto fiscal. Los impuestos directos sobre el excedente neto fiscal se han calculado:

impuestos directos sobre el excedente neto fiscal $=$ = impuesto de sociedades $+15 \%$ cuota líquida IRPF(renta mixta)

\subsubsection{Tipos medios sobre rentas del trabajo y del capital}

El cálculo de tipos medios impositivos pagados sobre cada renta se ha recogido en la Figura 7, siendo:

— tipo medio sobre rendimientos netos del trabajo = impuestos sobre rendimientos netos del trabajo/rendimientos netos del trabajo;

- tipo medio sobre excedente neto fiscal = impuestos sobre excedente neto fiscal /excedente neto fiscal.

Hemos incluído también el tipo medio efectivo pagado en sociedades:

— tipo medio sobre sociedades = impuestos sociedades/beneficio antes de impuestos en empresas con base liquidable positiva.

Figura 7

Tipos medios de impuestos directos (I)

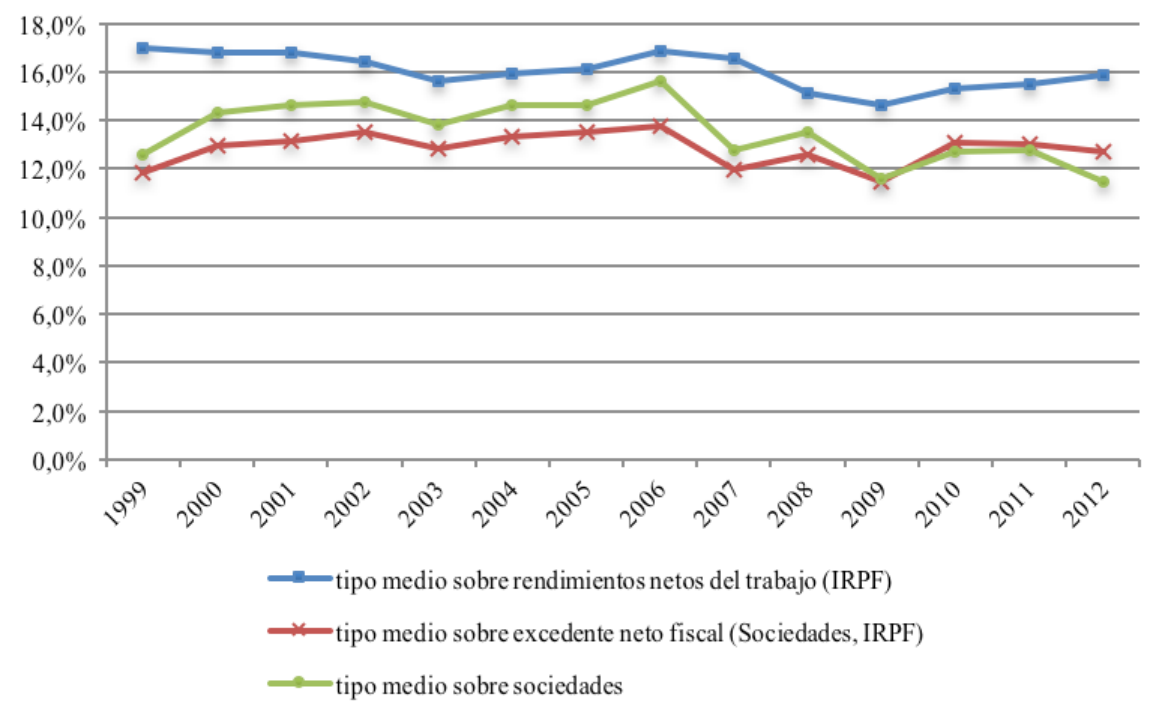

Fuente: elaboración propia a partir de datos de Hacienda Foral de Gipuzkoa. 
En los tres casos se observa un tendencia decreciente que alcanza valores mínimos en el ańo 2009, momento a partir del cual el tipo medio sobre rendimientos netos del trabajo sigue una tendencia ascendente hasta 2012; pero no sucede lo mismo con los otros dos tipos medios que, tras un repunte de un año, vuelen a descender hasta 2012. La presión fiscal sobre salarios está por encima de la presión sobre las rentas de capital a lo largo de todo el periodo, siendo en el ańo 2012 del 15,8\% y del 12,7\% respectivamente.

$\mathrm{Si}$ en lugar de contemplar la presión fiscal sobre las bases liquidables, lo hacemos sobre las macromagnitudes del PIBpm, los resultados se mantienen bastante estables para las rentas salariales, pero se ven muy reducidos en el caso de las rentas de capital. Lo hemos recogido en la figura 8 donde:

- tipo medio sobre salarios netos $($ EUSTAT $)=$ impuestos sobre rendimientos netos del trabajo/salarios netos (EUSTAT);

- tipo medio sobre excedente neto fiscal $($ EUSTAT) $=$ impuestos sobre excedente neto fiscal/excedente neto de explotación (EUSTAT).

Por ejemplo, en el año 2012 el tipo medio sobre el excedente neto del PIBpm es de 4,8\%, mientras que sobre el beneficio antes de impuestos de sociedades resulta un tipo medio de $12,7 \%$. En ese mismo ańo, el tipo medio sobre las rentas del trabajo según IRPF es del 15,8\%, y de 15,9\% sobre datos del PIBpm.

Figura 8

Tipos medios de impuestos directos (II)

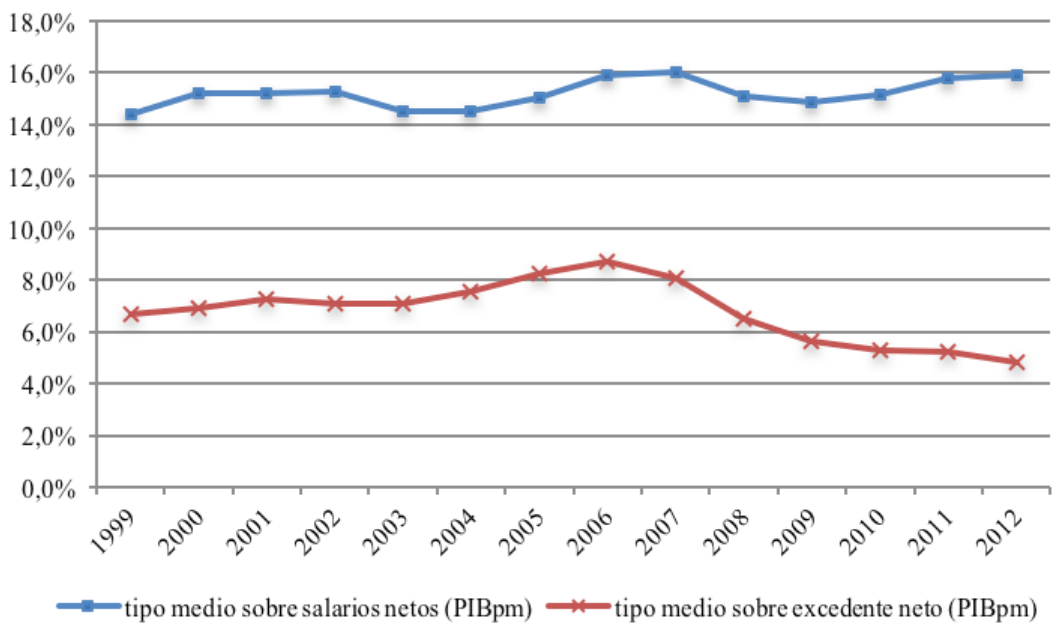

Fuente: elaboración propia a partir de datos de EUSTAT y Hacienda Foral de Gipuzkoa. 


\subsubsection{Bases imponibles de las rentas del PIBpm}

En la Figura 9 se recogen los porcentajes de rentas de trabajo y de capital que tributan frente a las contabilizadas en el PIBpm, quedando muy por debajo la tributación de las rentas de capital de la de las rentas del trabajo, diferencia que se acentúa de manera notable a partir de 2007: entre 2007 y 2012, el porcentaje sobre el excedente neto de explotación varía del 67,4\% al 37,4\% y el porcentaje sobre las rentas del trabajo lo hace entre un $96 \%$ en 2007 y un $100,2 \%$ del 2012.

Figura 9

Bases imponibles de las rentas del trabajo y del capital

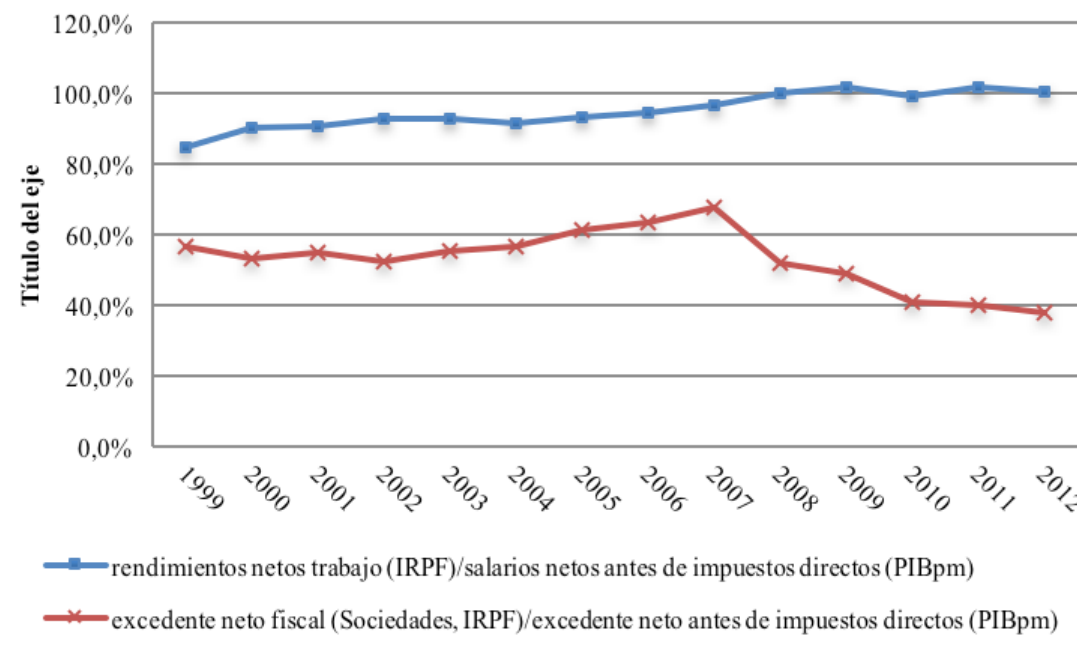

Fuente: elaboración propia a partir de datos de Eustat y Hacienda Foral de Gipuzkoa.

En la Figura 10 y la Figura 11 están representadas las bases imponibles por cada tipo de renta. 
Figura 10

Base imponible del excedente neto del PIB

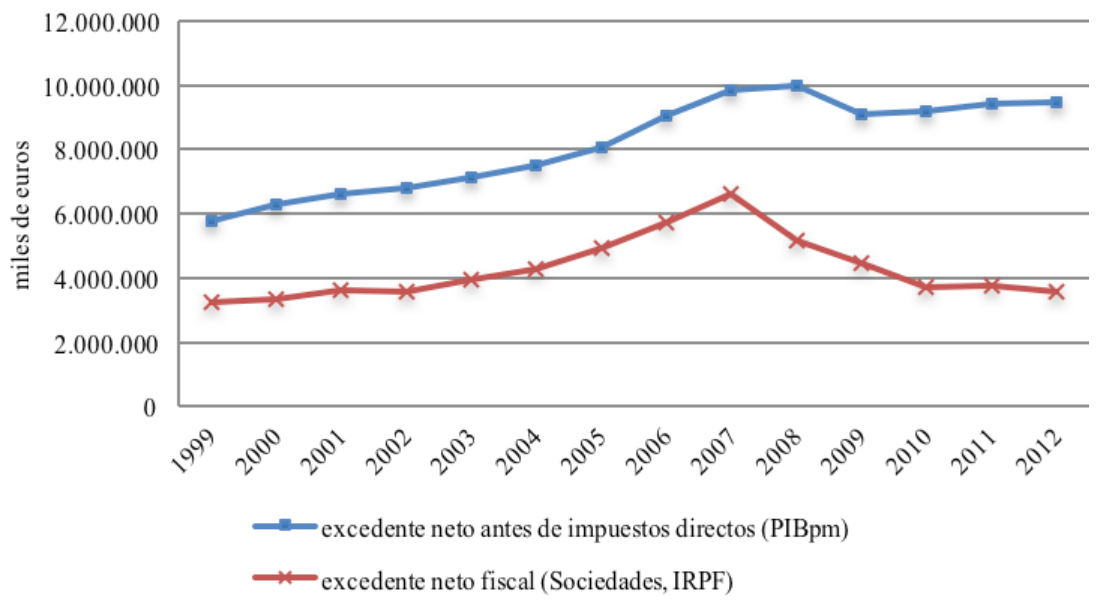

Fuente: elaboración propia a partir de datos de Eustat y Hacienda Foral de Gipuzkoa.

Figura 11

Base imponible de los salarios netos del PIBpm

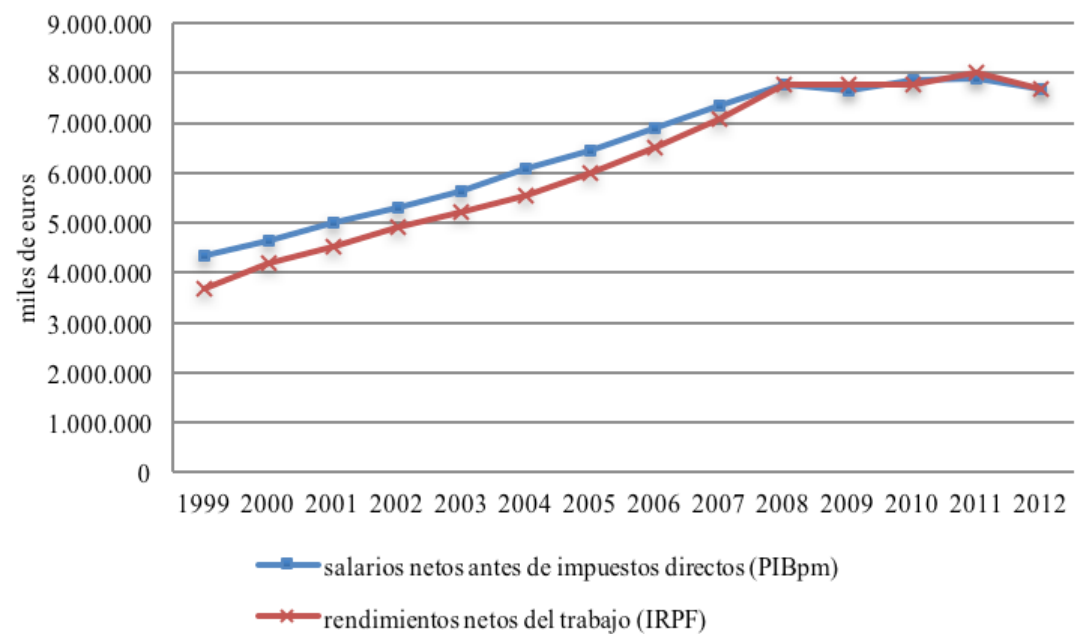

Fuente: elaboración propia a partir de datos de Eustat y Hacienda Foral de Gipuzkoa.

Con independencia de las dificultades metodológicas que aparecen al realizar comparaciones entre las magnitudes con las que se trabaja en las cuentas del PI- 
Bpm y en las bases imponibles de la Hacienda Foral, que están presentes a lo largo de todo el periodo analizado, resulta evidente que desde el comienzo de la crisis se produce un quiebro importante y creciente en la tributación relativa de las rentas de capital del PIB gipuzkoano que no tiene un paralelismo en las rentas del trabajo.

Excede al objetivo de este trabajo un análisis de las razones que puedan explicar en qué medida el comportamiento de la base imponible de las rentas de capital es imputable a la propia crisis y en qué medida la normativa fiscal está favoreciendo la desgravación de estas rentas, al margen de que, para el caso de Gipuzkoa, no hemos conseguido hasta el momento información suficientemente desagregada sobre el Impuesto de Sociedades como para abordar este estudio.

\subsubsection{Algunos resultados del impuesto de sociedades en Gipuzkoa}

Desde el inicio de la crisis se observa un reducción de un $60 \%$ en la recaudación por el impuesto de sociedades, pasando de 587 millones de euros en 2007 a 238 en 2012 (Figura 12).

Figura 12

Impuesto de sociedades

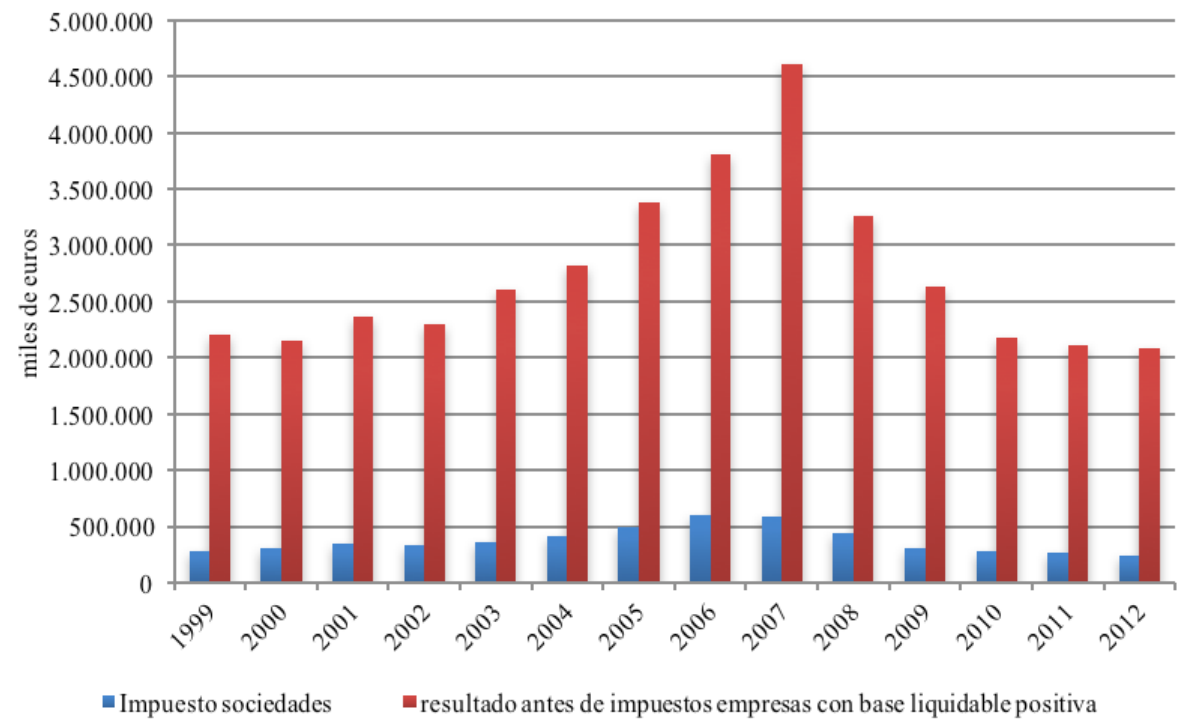

Fuente: elaboración propia a partir de datos de Hacienda Foral de Gipuzkoa.

En cuanto al resultado contable, la información más desagragada que se nos ha facilitado para el periodo 2008-2012 está sintetizada en los dos gráficos si- 
guientes. En la Figura 13 se ha referido el resultado contable total, el resultado contable positivo y el resultado contable negativo de todas las empresas a los valores obtenidos en 2008. Se observa un decrecimiento continuado en el resultado positivo junto a un protagonismo creciente del resultado negativo que, en 2012 conduce al resultado total a un valor negativo del $-54 \%$ del alcanzado en 2008 .

Figura 13

Resultado contable por tipo de resultado (base 2008)

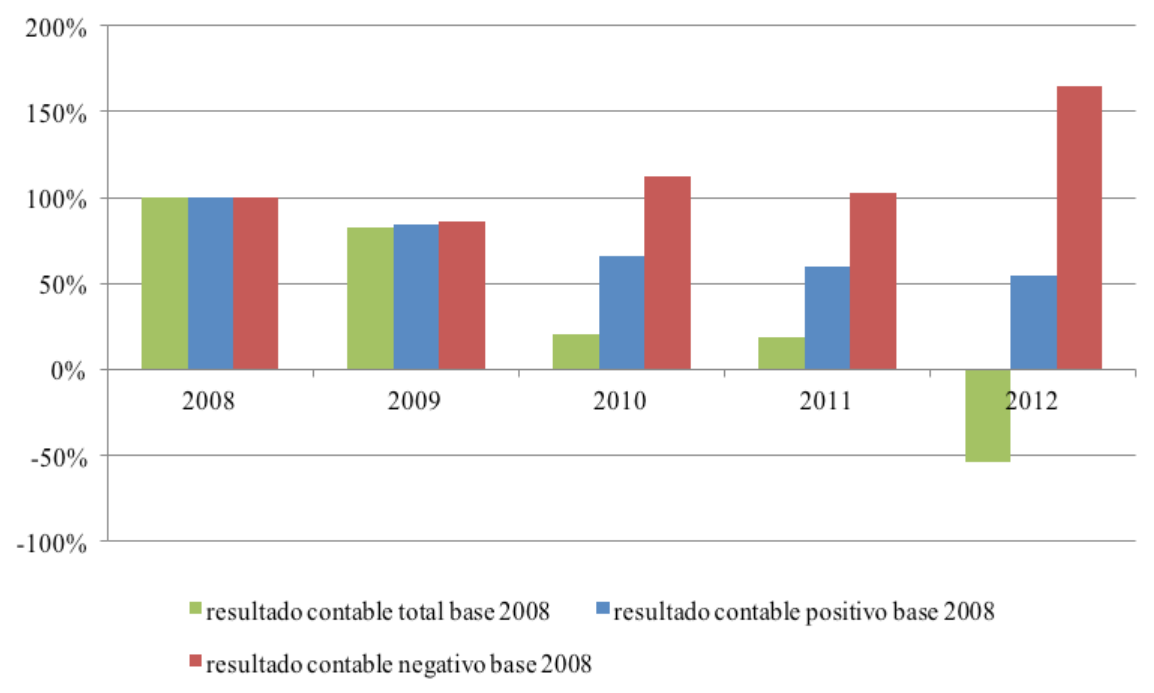

Fuente: elaboración propia a partir de datos de Hacienda Foral de Gipuzkoa.

Si se analiza el resultado por tipo de empresas, se observa una elevadísima volatilidad para el resultado contable de las empresas de crédito que oscila entre un $1.711 \%$ en 2009 y un $-321 \%$ en 2012 . Para las empresas no financieras, el resultado contable total disminuye de una manera persistente pero más moderada, llegando a alcanzar en 2012 un $-48 \%$ del obtenido en 2008 (Figura 14). 
Figura 14

Resultado contable por tipo de empresas (base 2008)

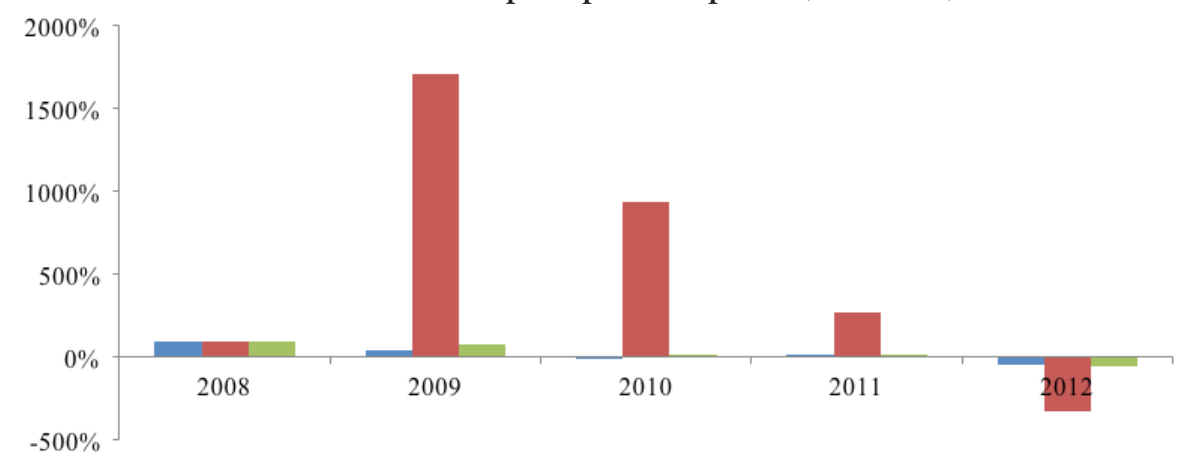

m resultado contable no financieras base 2008 "resultado contable crédito base 2008

resultado contable total base 2008

Fuente: elaboración propia a partir de datos de Hacienda Foral de Gipuzkoa.

\subsection{Fiscalidad directa y distribución de la renta}

En la Figura 15 siguiente hemos recalculado los componentes en rentas del PIBpm, teniendo en cuenta el efecto redistributivo de los impuestos directos so-

Figura 15

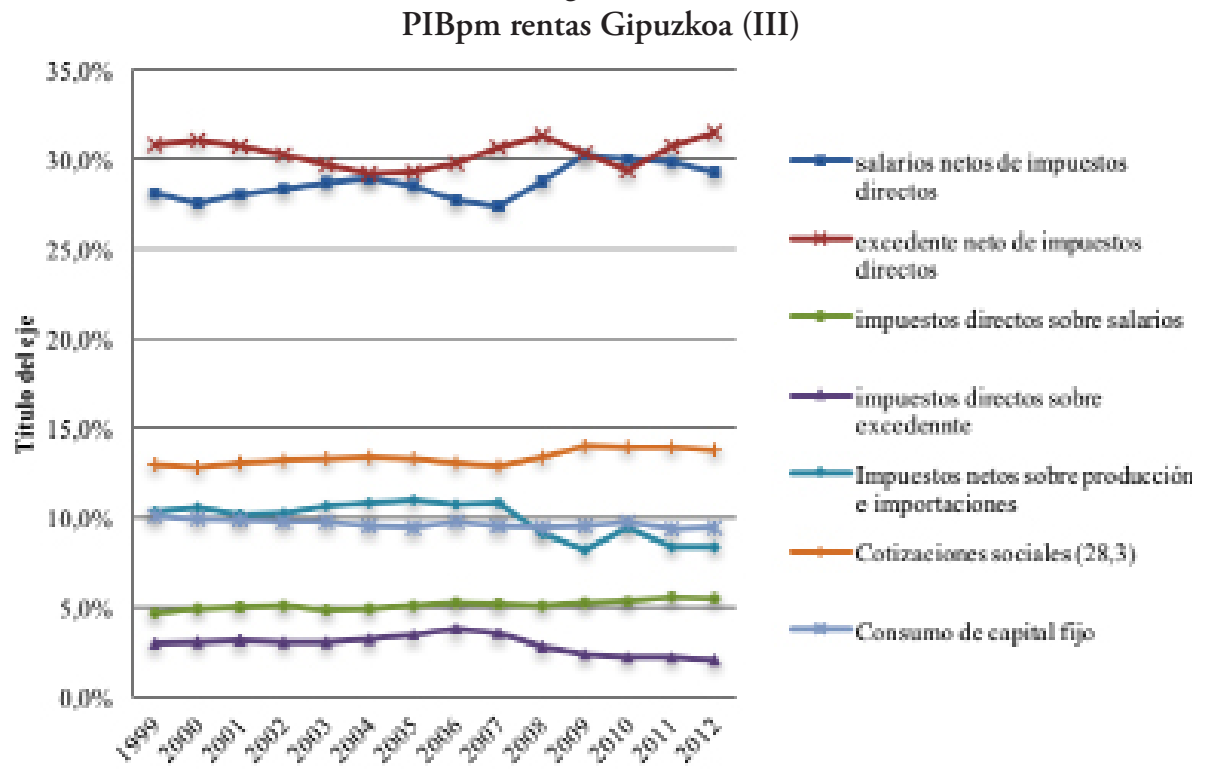

Fuente: elaboración propia a partir de datos de Eustat y Hacienda Foral de Gipuzkoa. 
bre las mismas. En esta tercera despomposición en rentas para el PIB, en la que hemos descontado los impuestos directos a los salarios netos (IRPF) y al excente neto de explotación (impuesto de sociedades y IRPF para las rentas mixtas), la participación de las rentas salariales en el PIB se sitúa por debajo de la de las rentas de capital a lo largo de todo el período, excepto en el año 2010 en el que la participación de los salarios en el PIB es del 30\% y la del excednte del 29,3\%. Mientras los salarios se mantienen entre un valor mínimo de 27,4\% en 2007 y un máximo de 30,3\% en 2009, el excedente lo hace entre un 29,2\% en 2004 y un $31,5 \%$ en 2012, produciéndose la máxima diferencia entre ambas series en el ańo 2000 (31\% y 27,6\%) y en 2007 (30,6\% y 27,4\%).

Figura 16 hemos recogido la relación entre el excedente explotación y los salarios (tasa excedente de explotación/salarios, que es una aproximación a la tasa de plusvalía) que se obtienen antes y después de deducir los impuestos directos de las rentas de trabajo y de capital. Ambas tasas, antes y después de impuestos, alcanzan valores máximos en 2000 y 2007 (105\% antes de impuestos y 113\% después en ambos ańos) y mínimos en 2010 (89\% y 98\%), ańo a partir del cual vuelven a crecer hasta el final del periodo (96\% y 108\% respectivamente en 2012).

La diferencia entre ambas tasas pone de manifiesto que el efecto redistributivo de los impuestos directos resulta favorable a las rentas de capital en todo el período. Esta serie alcanza un valor mínimo de 5\% en 2005, momento a partir del cual muestra una tendencia creciente hasta alcanzar un 12\% en 2012.

Figura 16

Efectos redistributivos de los impuestos directos

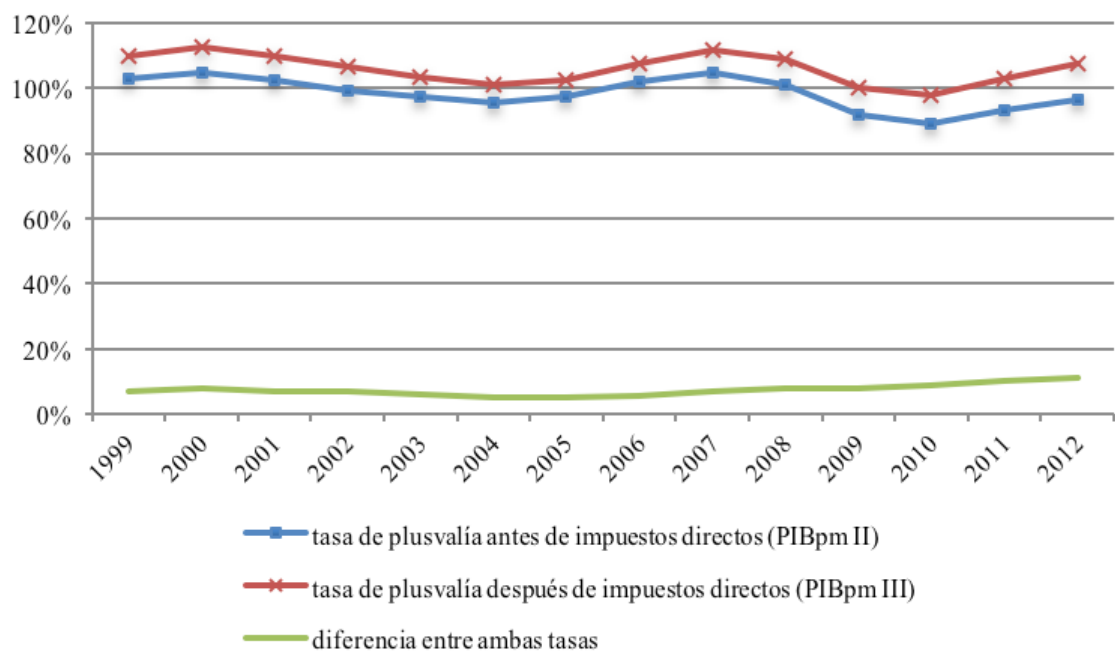

Fuente: elaboración propia a partir de datos de Eustat y Hacienda Foral de Gipuzkoa. 


\section{Remuneración, Productividad, Costes laborales unitarios (CLU)}

\subsection{Remuneración, en términos reales ${ }^{6}$}

Durante ese periodo la remuneración media por hora asalariada en Gipuzkoa, en términos reales (base 2012) ha sido la mostrada en la Figura 17, pasando de $22,37 € / \mathrm{h}$ a $24,64 € / \mathrm{h}$, es decir, un incremento del $10,13 \%$ en términos reales, aunque en los dos últimos ańos considerados (2011 y 2012) la remuneración real ha caído desde el máximo de 2010, cuando el salario medio por hora fue de $25,61 € / h$.

Figura 17

Remuneración real por hora asalariada, base 2012

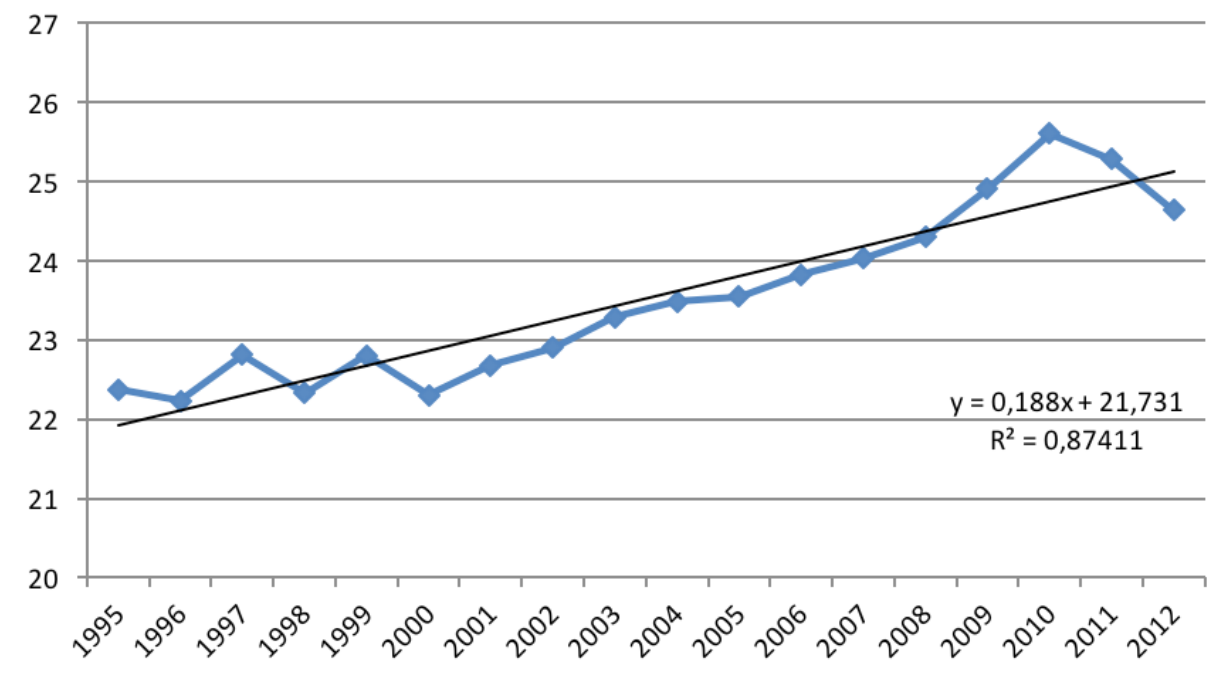

Fuente: elaboración propia, con datos de Eustat.

\subsection{Productividad real}

Consideramos que la remuneración de los asalariados se ha de deflactar con el IPC (índice de precios al consumo), debido a que los trabajadores gastan la renta percibida como salario en bienes y servicios finales de consumo, y es la variación del precio de estos bienes la que determina el poder adquisitivo de los salarios.

6 En la definición de Eustat, "Remuneración de los Asalariados» comprende toda la remuneración en efectivo y en especie a pagar por los empleadores a sus asalariados como contrapartida del trabajo realizado por estos durante el periodo contable. Se desglosa en Sueldos y salarios y Cotizaciones Sociales a cargo del empleador. 
Sin embargo, la productividad afecta a todos los bienes y servicios producidos en la economía, por lo que su nivel ha de armonizarse mediante el deflactor del PIB, que engloba la variación de los precios de todos los bienes y servicios. Así considerada, la productividad/hora de los asalariados guipuzcoanos, en el periodo 1995-2012, medida en términos reales con base en 2012, ha pasado de $35 € / \mathrm{h}$ en 1995 a $43 € / \mathrm{h}$ en 2012 , lo que supone un incremento del $23,45 \%$, habiendo aumentado en todos los años del periodo, excepto una leve caída entre 2003 y 2004.

La evolución de la productividad real queda reflejada en el siguiente gráfico:

Figura 18

Productividad real por hora asalariada, base 2012

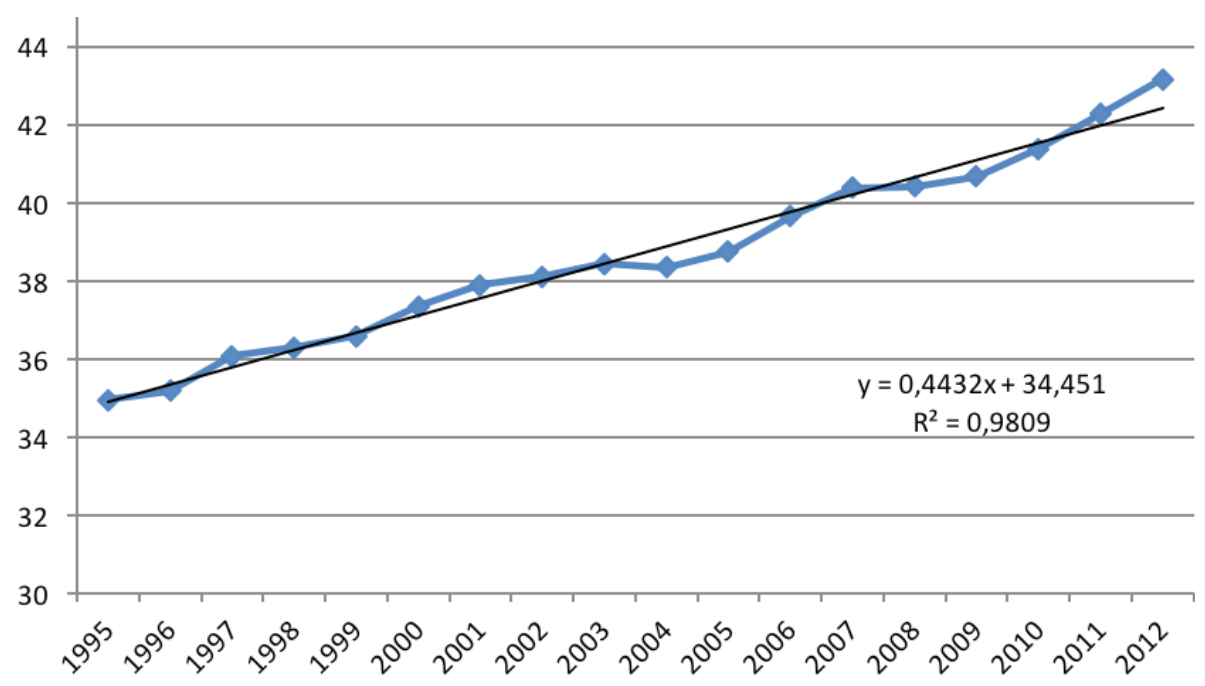

Fuente: elaboración propia, con datos de Eustat.

Por lo tanto, durante el periodo 1995-2012, la variación de la productividad real ha sido de un $23,45 \%$, para un incremento de los salarios reales de un $10,13 \%$.

Si en 1995 la diferencia entre la productividad/hora y el salario/hora era de un 50\% del salario, esa proporción ha aumentado hasta el $75 \%$ del año 2012 . 


\subsection{Costes laborales unitarios}

\subsubsection{Costes laborales unitarios «reales»}

En la literatura económica ortodoxa, se consideran costes laborales unitarios reales al conciente entre el salario/hora nominal dividido por la productividad/ hora nominal, lo que muestra la parte del valor ańadido bruto percibido por los asalariados cada año considerado. Para el periodo en cuestión, los CLU reales en Gipuzkoa han tenido la siguiente evolución:

Figura 19

Costes Laborales Unitarios «reales»

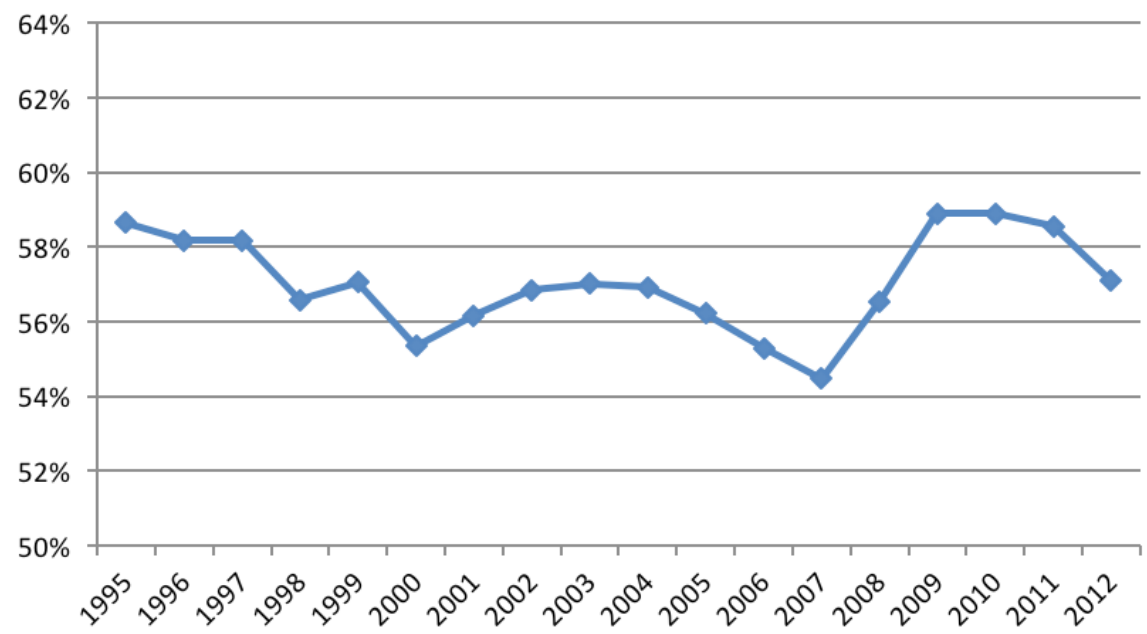

Fuente: elaboración propia, con datos de Eustat.

Se observa que los CLU reales han oscilado entre $54,5 \%$ y el $58,9 \%$, con mínimo en 2007 y máximos al principio del periodo y en los años 2009, 2010 y 2011, con un retroceso significativo en 2012.

\subsubsection{Costes laborales unitarios nominales}

En la economía convencional se llama costes laborales unitarios nominales al conciente entre el salario/hora nominal dividido por la productividad/hora real, lo que parece un contrasentido. Sin embargo, se utiliza la evolución de los CLU nominales, en comparación con la evolución de los precios, como un indicador de la inflación inducida por los costes laborales: si los CLU nominales aumentan más rápidamente que los precios, se supone que el incremento de salarios produce tensiones inflacionistas, $\mathrm{y}$ viceversa. 
Para la economía guipuzcoana, entre 1995 y 2012, la evolución de los CLU nominales y del IPC viene reflejada en este gráfico:

Figura 20

Costes Laborales Unitarios «nominales»

$\leadsto$ CLU nominal (salario nom/ productividad real) $\quad-$ IPC base $1995=39,98$

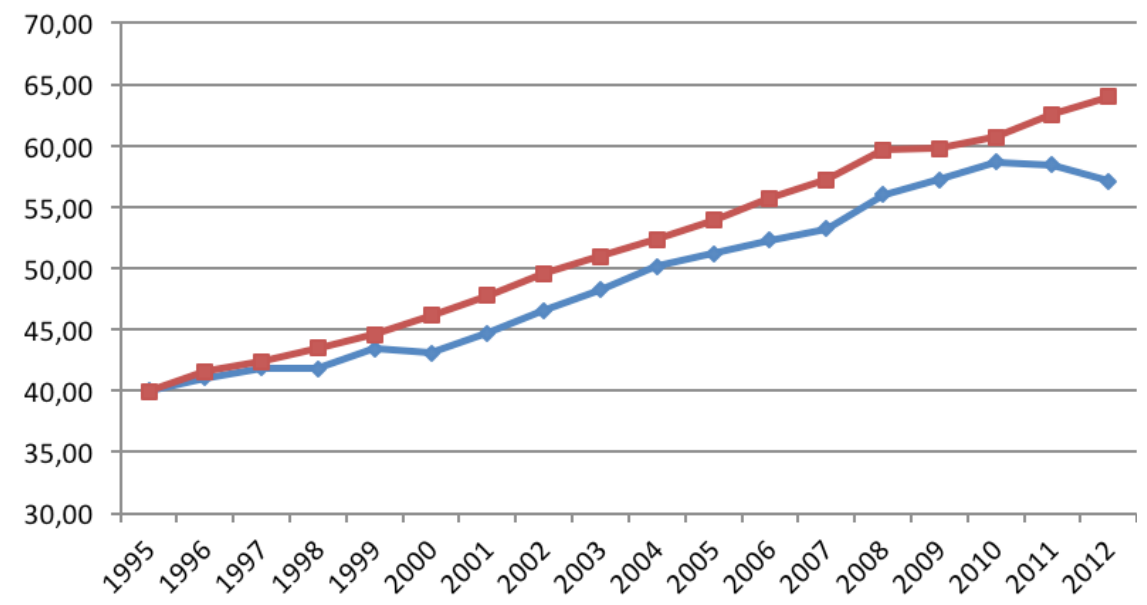

Fuente: elaboración propia, con datos de Eustat.

donde se observa que los CLU nominales han estado por debajo del IPC, con una divergencia mayor a partir de 2010. Según los economistas liberales esto significaría que los costes laborales no han producido tensiones inflacionistas.

\subsubsection{Costes laborales unitarios «deflactados»}

Finalmente vamos a considerar los CLU deflactados, donde los salarios han sido convertidos en salarios reales corrigiendo los incrementos en el IPC, y la productividad ha sido transformada en productividad real corrigiendo los incrementos generales de precios mediante el deflactor del PIB.

En este caso, la evolución de este indicador se muestra en el gráfico siguiente: 
Figura 21

Costes Laborales Unitarios deflactados, base 2012

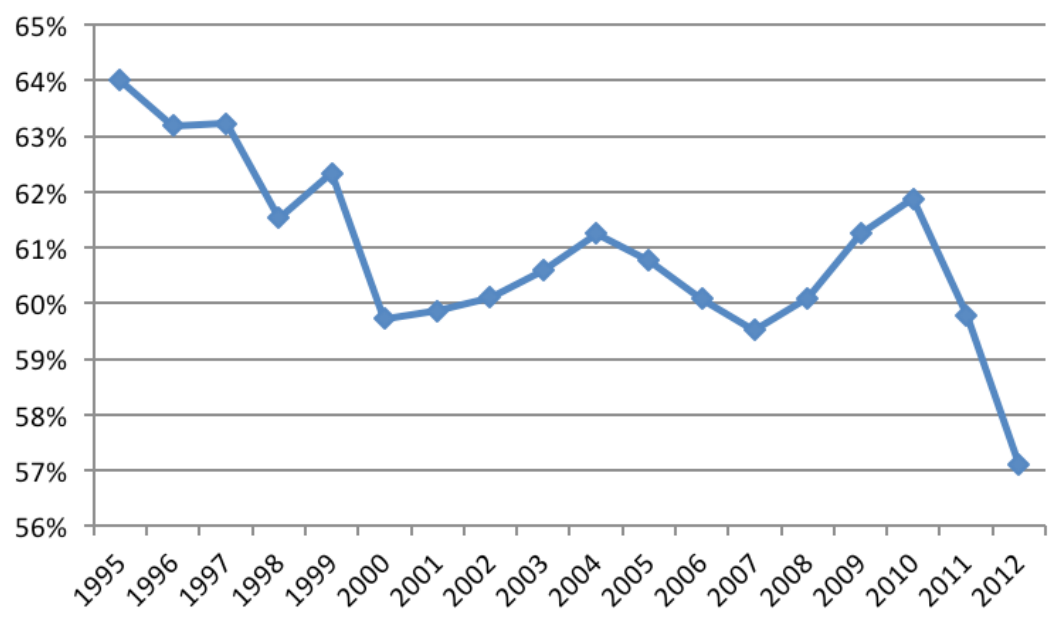

Fuente: elaboración propia, con datos de Eustat.

Es evidente, que en este caso, los CLU deflactados han tenido una evolución negativa, desde el 64\% hasta el 57\% (un retroceso del 10,8\%), consecuencia de las series analizadas en los primeros puntos: si para un aumento de los salarios reales del $10 \%$ la productividad real ha aumentado en un $23 \%$, esto supone que los CLU deflactados han pasado de 64, en el año 1995, a 57 en el año 2012.

\subsection{Resultados por sectores}

\subsubsection{Remuneración por sectores}

La evolución de los salarios reales (euros/hora, base 2012) aparece en la siguiente figura. 
Figura 22

Salario real / hora, por sectores, base 2012

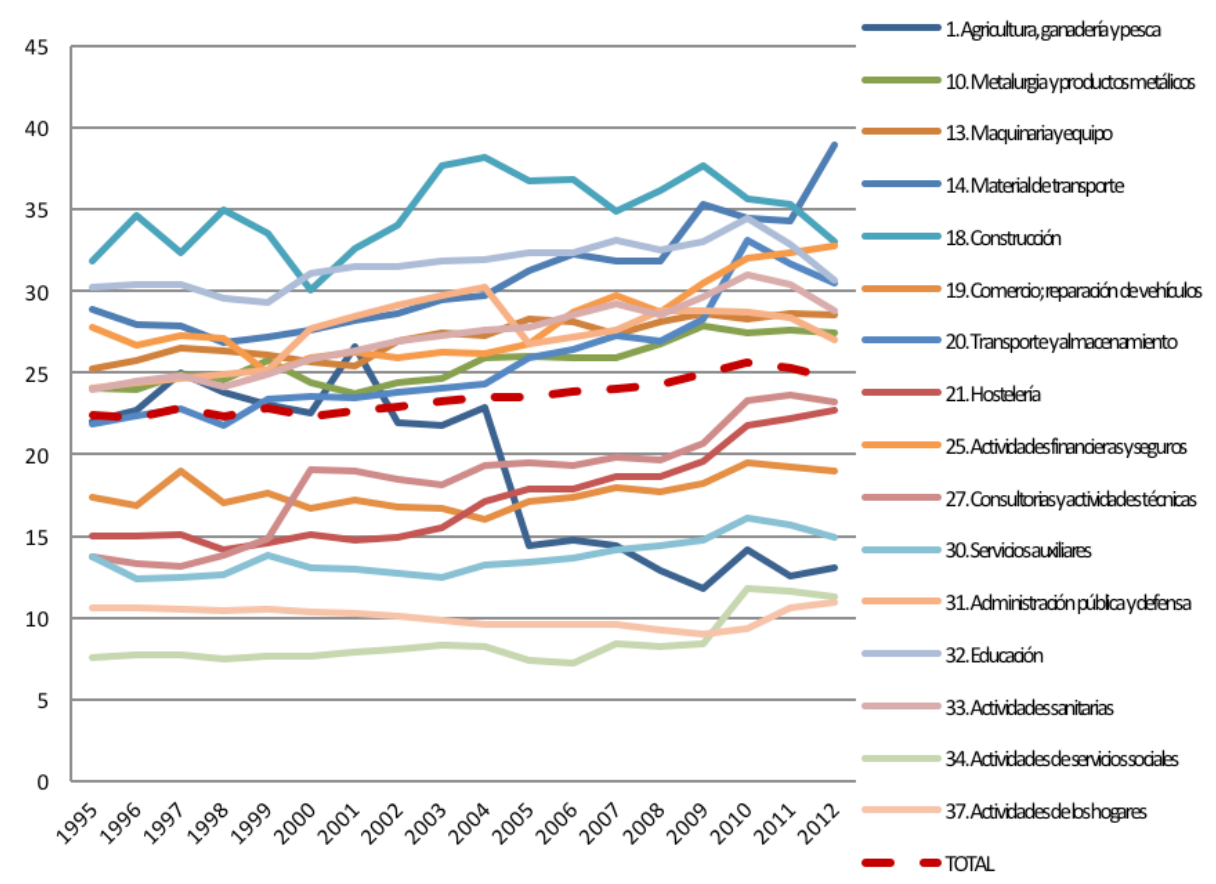

Fuente: elaboración propia, con datos de Eustat.

En el periodo 1995-2012, el salario/h ha aumentado menos que la media en los siguientes sectores: Agricultura (en el que ha disminuido), Construcción, Comercio, Servicios auxiliares, Educación y Actividades de los hogares. Desde que comenzó la crisis de 2007 hasta 2012, el sal/h ha disminuido en Agricultura, Construcción, Administración pública, Educación y Actividades sanitarias, pero el salario real medio, teniendo en cuenta todos los sectores, ha aumentado un $2,53 \%$. 


\section{Tabla 1}

Salario real/hora por sectores, variación (1995-2012) y (2007 y 2012)

\begin{tabular}{lrrr}
\hline \multicolumn{1}{c}{ Salario/h real por sector } & 2012 & var $95-12$ & var $07-12$ \\
\hline 1. Agricultura, ganadería y pesca & 13,04 & $-40,76 \%$ & $-9,81 \%$ \\
10. Metalurgia y productos metálicos & 27,45 & $13,96 \%$ & $5,91 \%$ \\
13. Maquinaria y equipo & 28,56 & $13,17 \%$ & $4,36 \%$ \\
14. Material de transporte & 38,97 & $34,97 \%$ & $22,44 \%$ \\
18. Construcción & 33,04 & $3,89 \%$ & $-5,28 \%$ \\
19. Comercio; reparación de vehículos & 18,97 & $9,09 \%$ & $5,66 \%$ \\
20. Transporte y almacenamiento & 30,46 & $39,15 \%$ & $11,66 \%$ \\
21. Hostelería & 22,73 & $51,35 \%$ & $22,11 \%$ \\
25. Actividades financieras y seguros & 32,78 & $18,10 \%$ & $10,41 \%$ \\
27. Consultorias y actividades técnicas & 23,20 & $68,93 \%$ & $16,77 \%$ \\
30. Servicios auxiliares & 14,95 & $8,87 \%$ & $5,26 \%$ \\
31. Administración pública y defensa & 26,98 & $12,36 \%$ & $-2,27 \%$ \\
32. Educación & 30,63 & $1,28 \%$ & $-7,46 \%$ \\
33. Actividades sanitarias & 28,76 & $20,11 \%$ & $-1,44 \%$ \\
34. Actividades de servicios sociales & 11,27 & $48,63 \%$ & $34,06 \%$ \\
37. Actividades de los hogares & 10,98 & $3,21 \%$ & $14,23 \%$ \\
\hline TOTAL & 24,64 & $10,13 \%$ & $2,53 \%$ \\
\hline
\end{tabular}

Fuente: elaboración propia, con datos de Eustat.

\subsubsection{CLUs reales por sectores}

A continuación, en la Figura 23 se detalla la evolución de los CLU en los sectores analizados ${ }^{7}$, sin tener en cuenta la parte correspondiente a los Impuestos Indirectos generados en cada sector. En la Tabla 2 se recoge la diferencia de los CLU así calculados entre el principio y el final del periodo considerado (19952012), y también, de forma más específica, en los años posteriores al estallido de la crisis financiera (2007-2012).

7 Con respecto a los CLU, hay que señalar que su cálculo por sectores es aproximado. Al hacer la valoración estadística del PIB, el Eustat recoge el Valor Añadido Bruto (VAB) de cada sector, y a la suma de dichos valores se le añade el montante de los Impuestos Indirectos. De esta manera, en cada uno de los sectores no aparece el total del Producto agregado (porque no aparece su parte correspondiente de Impuestos Indirectos), lo que hace que la productividad/hora de cada sector parezca menor, lo que a su vez implica unos CLU mayores. Por este motivo, en la Figura 23 hemos tomado en cuenta los CLU a partir del VAB de cada sector, pero para obtener datos más ajustados a la realidad hemos hecho, por otra parte en la Figura 24 un prorrateo de los Impuestos Indirectos por sector, para obtener los CLU correspondientes al Producto Bruto generado en cada uno de los sectores. 
Figura 23

CLU reales por sectores (sin impuestos indirectos)

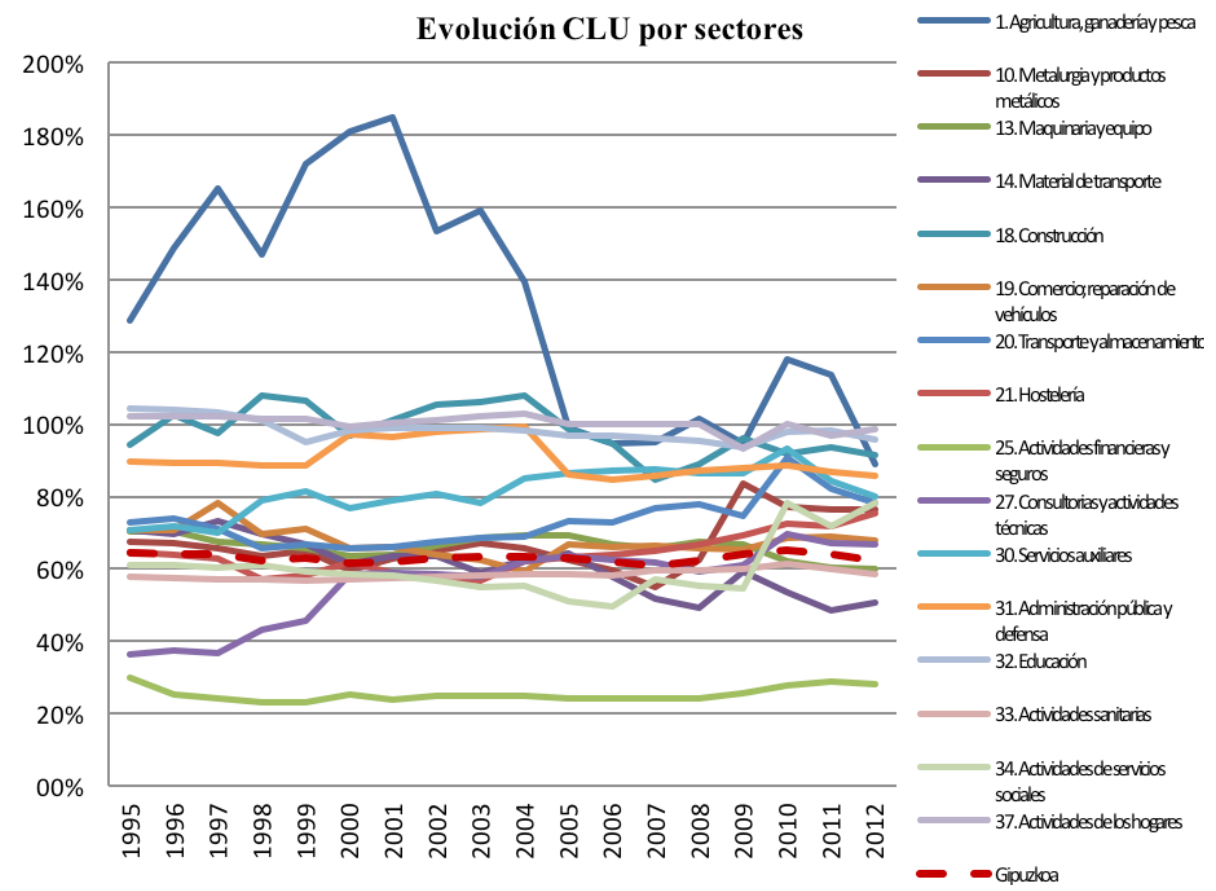

Fuente: elaboración propia, con datos de Eustat.

En los 16 sectores que estamos analizando, los CLUr (sin tener en cuenta los impuestos indirectos) en 2012 eran superiores a la media de Gipuzkoa $(62,4)$, excepto en Maquinaria y equipo, Actividades sanitarias (ambos cerca de la media), Material de transporte, y Actividades financieras y seguros, este último sector con los CLU menores de los 38 sectores $(28,3)$.

En el periodo más largo que estamos analizando, es decir, entre 1995 y 2012, los CLUr han disminuido un 3,13\% en Gipuzkoa, con comportamientos muy diferentes según los sectores: han aumentado en 7 sectores (Consultorías, Servicios sociales, Hostelería, Servicios auxiliares, Metalurgia, Transporte y Actividades sanitarias), con descensos en los otros 9 sectores analizados.

Sin embargo, en los años que van de 2007 a 2012, los CLUr han aumentado en Gipuzkoa un 2,64\% de media, con ascensos en 9 sectores (sobre todo en Metalurgia, Sanidad, Actividades financieras y Hostelería) y descensos en los otros 7, especialmente en Maquinaria-equipo y en Servicios auxiliares. 
Tabla 2

CLU reales por sectores (sin impuestos indirectos), variación entre 1995 y 2012, variación entre 2007 y 2012

\begin{tabular}{lrrr}
\hline \multicolumn{1}{c}{ Costes laborales unitarios gipuzkoa } & 2012 & var $95-12$ & var $07-12$ \\
\hline 1. Agricultura, ganadería y pesca & $89,0 \%$ & $-30,90 \%$ & $-6,42 \%$ \\
10. Metalurgia y productos metálicos & $76,3 \%$ & $12,88 \%$ & $38,47 \%$ \\
13. Maquinaria y equipo & $60,0 \%$ & $-14,88 \%$ & $-8,55 \%$ \\
14. Material de transporte & $50,6 \%$ & $-28,37 \%$ & $-2,16 \%$ \\
18. Construcción & $91,3 \%$ & $-3,37 \%$ & $7,98 \%$ \\
19. Comercio; reparación de vehículos & $67,7 \%$ & $-4,37 \%$ & $1,83 \%$ \\
20. Transporte y almacenamiento & $78,2 \%$ & $7,11 \%$ & $1,93 \%$ \\
21. Hostelería & $75,4 \%$ & $16,78 \%$ & $15,71 \%$ \\
25. Actividades financieras y seguros & $28,3 \%$ & $-5,40 \%$ & $16,69 \%$ \\
27. Consultorías y actividades técnicas & $66,7 \%$ & $82,80 \%$ & $8,27 \%$ \\
30. Servicios auxiliares & $80,1 \%$ & $13,35 \%$ & $-8,40 \%$ \\
31. Administración pública y defensa & $85,6 \%$ & $-4,36 \%$ & $-0,34 \%$ \\
32. Educación & $95,6 \%$ & $-8,38 \%$ & $-0,61 \%$ \\
33. Actividades sanitarias & $58,6 \%$ & $1,13 \%$ & $-1,74 \%$ \\
34. Actividades de servicios sociales & $78,1 \%$ & $28,27 \%$ & $36,97 \%$ \\
37. Actividades de los hogares & $98,5 \%$ & $-3,63 \%$ & $-1,48 \%$ \\
\hline Gipuzkoa & $62,4 \%$ & $-3,13 \%$ & $2,64 \%$ \\
\hline
\end{tabular}

Nota: Filas en rojo: sectores en los que los Costes Laborales Unitarios (reales) han aumentado entre los años 1995 y 2012.

Fuente: elaboración propia, con datos de Eustat.

En la Figura 24 y en la Tabla 3 aparecen los CLU por sector prorrateando los Impuestos Indirectos recaudados cada año, entre los diferentes sectores según su parte en el VAB total. Como se puede apreciar, en este caso en el que se considera la productividad total de cada sector, los CLU resultan algo menores (en torno a 6 puntos inferior de media), aunque su evolución en los periodos considerados es similar a la comentada en la tabla anterior, en la que aparecían los CLU sin Impuestos Indirectos. 
Figura 24

CLU reales por sectores (con impuestos indirectos prorrateados)
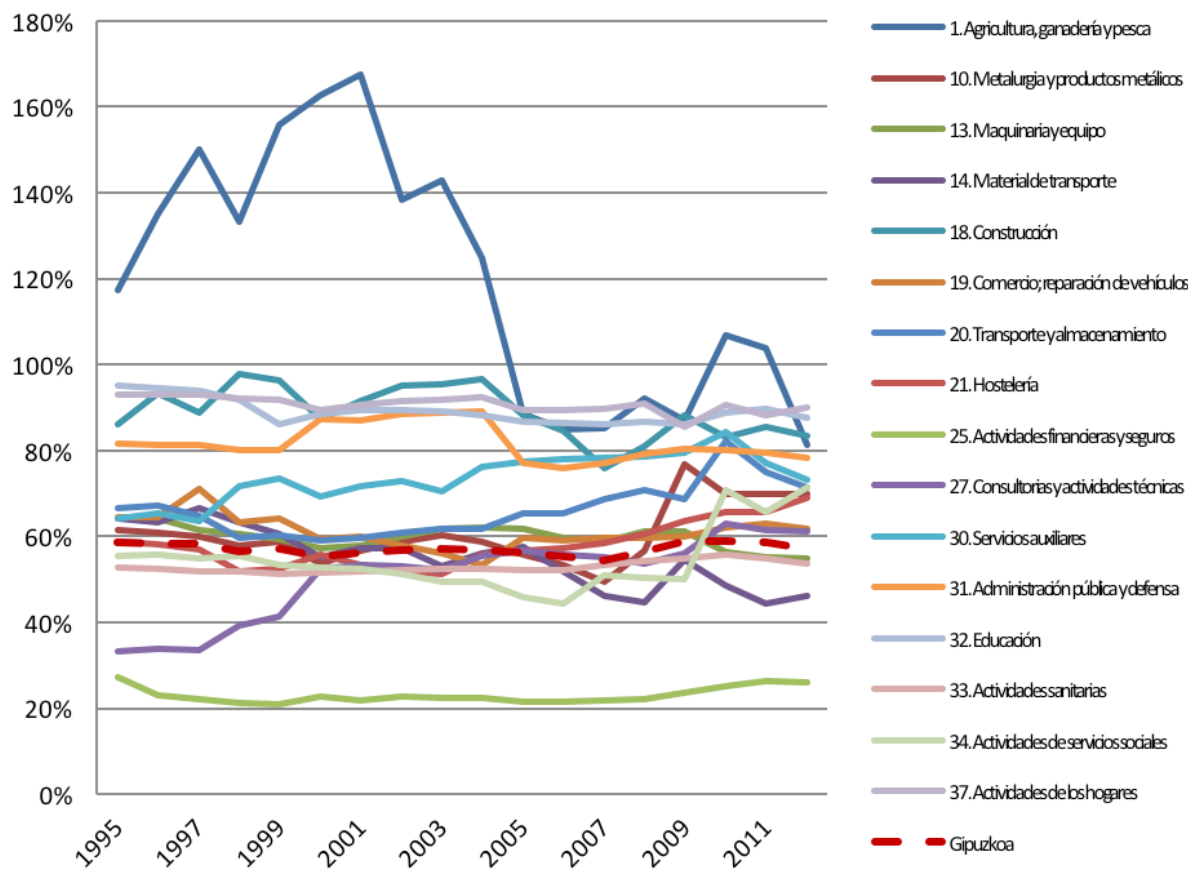

Fuente: elaboración propia, con datos de Eustat.

De esta forma, en los 16 sectores analizados, los CLUr en 2012 (tomando en cuenta el Producto Bruto de cada sector, incluidos los impuestos indirectos) eran superiores a la media de Gipuzkoa $(57,1)$, excepto en Maquinaria y equipo, Actividades sanitarias (ambos cerca de la media), Material de transporte, y Actividades financieras y seguros, este último sector con los CLU menores de los 38 sectores $(25,9)$. Es decir, que en la comparativa entre sectores el resultado es el mismo que habíamos obtenido antes, aunque consideramos que los CLU así calculados reflejan mejor la realidad de cada sector.

En el periodo 1995-2012 los CLUr han disminuido un 2,6\% en Gipuzkoa, con comportamientos muy diferentes según los sectores: han aumentado en Consultorías, Servicios sociales, Hostelería, Servicios auxiliares, Metalurgia, Transporte y Actividades sanitarias, con descensos en el resto de los 16 sectores analizados.

Sin embargo, en los años que van de 2007 a 2012, los CLUr han aumentado casi todos los sectores, con un incremento medio del 4,8\%, y con descensos en Maquinaria y equipo, Servicios auxiliares y Agricultura. 
Tabla 3

CLU reales por sectores (con impuestos indirectos prorrateados), variación entre 1995 y 2012, variación entre 2007 y 2012

\begin{tabular}{lccc}
\hline \multicolumn{1}{c}{ Costes laborales unitarios gipuzkoa } & 2012 & var $95-12$ & var $07-12$ \\
\hline 1. Agricultura, ganadería y pesca & $81,4 \%$ & $-30,55 \%$ & $-4,44 \%$ \\
10. Metalurgia y productos metálicos & $69,8 \%$ & $13,45 \%$ & $41,40 \%$ \\
13. Maquinaria y equipo & $54,9 \%$ & $-14,45 \%$ & $-6,61 \%$ \\
14. Material de transporte & $46,2 \%$ & $-28,01 \%$ & $-0,09 \%$ \\
18. Construcción & $83,5 \%$ & $-2,89 \%$ & $10,26 \%$ \\
19. Comercio; reparación de vehículos & $61,9 \%$ & $-3,89 \%$ & $3,98 \%$ \\
20. Transporte y almacenamiento & $71,5 \%$ & $7,65 \%$ & $4,08 \%$ \\
21. Hostelería & $69,0 \%$ & $17,36 \%$ & $18,15 \%$ \\
25. Actividades financieras y seguros & $25,9 \%$ & $-4,93 \%$ & $19,16 \%$ \\
27. Consultorías y actividades técnicas & $61,0 \%$ & $83,72 \%$ & $10,56 \%$ \\
30. Servicios auxiliares & $73,2 \%$ & $13,91 \%$ & $-6,46 \%$ \\
31. Administración pública y defensa & $78,3 \%$ & $-3,88 \%$ & $1,77 \%$ \\
32. Educación & $87,5 \%$ & $-7,92 \%$ & $1,50 \%$ \\
33. Actividades sanitarias & $53,6 \%$ & $1,63 \%$ & $0,33 \%$ \\
34. Actividades de servicios sociales & $71,4 \%$ & $28,91 \%$ & $39,87 \%$ \\
37. Actividades de los hogares & $90,1 \%$ & $-3,14 \%$ & $0,61 \%$ \\
\hline Gipuzkoa & $57,1 \%$ & $-2,65 \%$ & $4,81 \%$ \\
\hline
\end{tabular}

Nota: Filas en rojo: sectores en los que los Costes Laborales Unitarios (reales) han aumentado entre los ańos 1995 y 2012.

Fuente: elaboración propia con datos de Eustat.

\section{Conclusiones}

Si se mide la distribución de la renta en términos brutos, la participación de las rentas del trabajo se sitúa por encima de las del capital durante todo el periodo, acentuándose esta diferencia a partir de 2008, y siendo en 1995 de un $46 \%$ frente a un $44 \%$ y de un $49 \%$ frente a un $43 \%$ en 2012 , al final del periodo.

Medida en términos netos, esto es, descontando el consumo de capital fijo y las cotizaciones a la seguridad social, la distribución entre el excedente de explotación y los salarios resulta más equitativa. La diferencia a favor de salarios también es algo más pronunciada a partir de 2008 y máxima en 2010 (35\% frente a 32\%).

Al descontar los impuestos directos, la distribución de la renta disponible resulta claramente a favor de las rentas de capital todo el período, excepto en el 
año 2010 en el que la participación de los salarios en el PIB fue del 30\% y la del excedente del 29,3\%.

La medida del efecto redistributivo de los impuestos directos, favorable a las rentas del capital, la hemos calculado por su impacto en la tasa excedente neto de explotación/salarios netos, una aproximación a la tasa de plusvalía. Tanto antes como después de impuestos, la tasa alcanza valores máximos en 2000 y 2007 (113\% antes de impuestos y 105\% después) y mínimos en 2010 (98\% y 89\% respectivamente), ańo a partir del cual vuelve a recuperarse. La diferencia entre ambas tasas resulta favorable a las rentas de capital todo el periodo, con un mínimo de $5 \%$ en 2005 , momento a partir del cual muestra una tendencia creciente hasta alcanzar un $12 \%$ en 2012.

La base imponible del excedente neto de explotación presenta, a efectos tributarios, una importante desviación negativa y de tendencia ascendente respecto a su participación en el PIBpm, especialmente a partir del ejercicio 2008, desviación que no se encuentra en las rentas salariales. Hemos encontrado también, entre 2008 y 2012, un comportamiento errático en el resultado contable de las empresas de crédito y un descenso mantenido en el resultado contable positivo agregado. Excede al objetivo de este trabajo un análisis de las razones que puedan explicar en qué medida el comportamiento de la base imponible de las rentas de capital es imputable a la propia crisis y en qué medida la normativa fiscal está favoreciendo la desgravación de estas rentas, al margen de que no hemos conseguido hasta el momento información suficientemente desagregada sobre el Impuesto de Sociedades como para abordar este estudio.

Queda pendiente de evaluación el efecto de los efectos redistributivo de los impuestos indirectos (IVA fundamentalmente), que no son soportados de manera homogénea por ambos tipos de renta.

La productividad real por hora trabajada (deflactada por el PIB) ha aumentado en Gipuzkoa desde 35€/h en 1995 hasta $43 € /$ h en 2012.

Por su parte, los Costes Laborales Unitarios (CLU), indicador que muestra la parte de la renta agregada producida que se lleva el trabajador, se han mantenido entre un $54 \%$ y un $58 \%$ en el periodo considerado. Aumentaron entre 2007 y 2009, pero a partir de ahí han tenido un comportamiento a la baja. Entre 2007 y 2012 los CLU han aumentado un 4,8\% en Gipuzkoa, con aumentos mayores a la media especialmente en Metalurgia, Actividades de los hogares, Hostelería, Actividades financieras, Construcción y Consultorías, y descensos en los otros 7, especialmente en Maquinaria-equipo y en Servicios auxiliares. 


\section{Bibliografía}

Álvarez Peralta, Ignacio y Luengo Escalonilla, Fernando (2011): Competitividad y costes laborales en la UE: más allá de las apariencias, WP02/11. ICEI. Madrid.

Bilbao, Javier (2013): «Salarios y costes laborales unitarios en la economía española», Lan Harremanak. Revista de Relaciones Laborales, n.o 27, 2012.

Castrillón, Verónica, Zendoia, Jose Mari y Zubiri, Jon Bernat (2016a): «Diagnóstico del empleo en Gipuzkoa». Lan Harremanak. Revista de Relaciones Laborales, 342016 (1).

Castrillón, Verónica, Zendoia, Jose Mari y Zubiri, Jon Bernat (2016c): «Indicadores socio-laborales y viabilidad sectorial de la reducción del tiempo de trabajo en Gipuzkoa", Lan Harremanak. Revista de Relaciones Laborales, 34-2016 (1).

Castrillón, Verónica, Zendoia, Jose Mari y Zubiri, Jon Bernat (2016d): «Propuestas de reducción del tiempo de trabajo en Gipuzkoa», Lan Harremanak. Revista de Relaciones Laborales, n. ${ }^{\circ}$ 34, 2016 (1).

CES, Consejo Económico y Social España (2013): Informe 03/2013 Distribución de la renta en España: desigualdad, cambios estrructurales y ciclos, CES España.

ED, Economía Digital (2015): El FMI admite que la desigualdad dificulta el crecimiento económico. Barcelona, p. 1.

Fernández DíAz, Andrés (2008): Efecto de la seguridad social en la redistribución de la renta. Informe promovido por el Ministerio de Trabajo y Asuntos Sociales.

Lindenboim, Javier (2008): «Distribución funcional del ingreso, un tema olvidado que requiere atención», Revista Latinoamericana de Economía, vol. 39, núm. 153, abril-junio, 83-117, Universidad Nacional Autónoma de México Distrito Federal, México.

OECD (2015): In It Together: Why Less Inequality Benefits, OECD Publishing.

Riechman, Jorge y Recio, Albert (1997): Quien parte y reparte... El debate sobre la reducción del tiempo de trabajo, Barcelona, Icaria. 